\title{
Optimisme sebagai Prediktor Psikologis pada Mahasiswa Kebidanan
}

\author{
Sugiarti A Musabiq ${ }^{1}$, Eko Aditya Meinarno² \\ ${ }^{1,2}$ Fakultas Psikologi, Universitas Indonesia \\ Jl. Lkr. Kampus Raya, Pd. Cina, Beji, Kota Depok, Jawa Barat 16424 \\ Email: musabiqsugiarti2017@gmail.com
}

\begin{abstract}
ABSTRAK
Penelitian ini dilakukan untuk mengetahui hubungan optimisme dengan self-esteem, career decision-making self-efficacy, hardiness, dan resiliensi pada mahasiswa kebidanan. Penelitian ini merupakan penelitian kuantitatif dengan desain korelasional. Sampel dari penelitian ini adalah mahasiswa program diploma III kebidanan yang berada di wilayah provinsi DKI Jakarta, Jawa Barat, Banten, dan Sumatera Barat. Secara keseluruhan, 571 mahasiswa program Diploma III kebidanan berpartisipasi dengan cara mengisi kuesioner alat ukur yang terdiri dari LOT-R yang dikembangkan oleh Scheier, Carver, dan Bridges (1994), Rosenberg's Selfesteem Scale yang dikembangkan oleh Rosenberg (1965), CDSE-SF yang dikembangkan oleh Taylor dan Betz (1983), DRS 15-R yang dikembangkan oleh Paul T. Bartone (2007) dan telah diadaptasi di Indonesia oleh Lukman (2008) dan CD-RISC yang dikembangkan oleh Connor dan Davidson (2003) dan telah diadaptasi oleh Campbell-Sills dan Stein (2007). Hasil penelitian menunjukkan bahwa keempat variabel memiliki hubungan yang positif dengan optimisme, yang berarti apabila keempat variabel ini mengalami peningkatan maka optimisme pada diri mahasiswa juga akan meningkat. Selain itu variabilitas skor keempat variabel dapat diprediksi dari hubungannya dengan optimisme.
\end{abstract}

Kata kunci: Optimisme, CDSE, Hardiness, Resiliensi, Self-esteem

\section{Optimsm As a Psychological Predictors in Midwifery Students}

\begin{abstract}
This research was conducted to investigate the correlation between optimism and self-esteem, career decisionmaking self-efficacy, hardiness, and resilience among midwifery college students. This research is quantitative with correlational design. Sample used are midwifery college students in the area of Jakarta, Banten, West Sumatera and West Java. Overall, 571 midwifery student was participated in this research by filling out the questionnaire consisting of LOT-R constructed by Scheier, Carver, and Bridges (1994), Rosenberg's Selfesteem Scale constructed by Rosenberg (1965), CDSE-SF that constructed by Taylor and Betz (1983), DRS 15$\mathrm{R}$ that constructed by Paul T. Bartone (2007) and was adapted by Lukman in Indonesia (2008) and CD-RISC constructed by Connor and Davidson (2003) and was adapted by Campbell-Sills and Stein (2007). The result showed that four variable had a positive correlation with optimism, which mean that if all increased, score of optimism on the midwifery students will also increase. On the other hand, variablity score of four variable was predictable by they correlation with optimism.
\end{abstract}

Keywords: Optimism, CDSE, Hardiness, Resiliency, Self-esteem

\section{Pendahuluan}

Optimisme merupakan salah satu konstruk psikologi yang dapat berpengaruh pada kehidupan individu. Menurut Scheier, Carver, dan Bridges optimisme didefinisikan sebagai kecenderungan individu tentang ekspektasi atau pengharapan positif pada masa depan. ${ }^{1}$ Menurut Schulman dalam Gillham, Shatte, Reivich, \& Seligman, seseorang yang optimis akan cenderung terkait dengan prestasi akademik yang tinggi di perguruan tinggi, dan meningkatnya produktifitas kerja. ${ }^{2}$ Orang yang optimis juga lebih memiliki keyakinan tentang 
masa depan yang membawa mereka untuk melanjutkan upaya menuju tujuan yang diharapkan walaupun dalam pencapaiannya terdapat beberapa kesulitan. ${ }^{3}$ Melihat adanya pengaruh positif dari optimisme pada kehidupan, maka penting bagi seorang individu untuk memiliki optimisme. Salah satu kelompok individu yang dirasa penting untuk memiliki optimisme dan menjadi sorotan dalam penelitian ini adalah mahasiswa kebidanan.

Mahasiswa kebidanan sebagai calon bidan, di masa depan mereka akan memiliki peran dan posisi penting seperti dalam hal penurunan Angka Kematian Ibu (AKI) dan Angka Kesakitan serta Kematian Bayi (AKB). ${ }^{4}$ Bidan juga cukup berperan penting dalam memberikan pelayanan Keluarga Berencana (KB) $(51,9 \%) .{ }^{5}$ Hasil survei United Nation for Children Fun (UNICEF) juga menunjukkan bahwa bidan berperan penting dalam memberikan pelayanan kesehatan dan bantuan melahirkan pada ibu hamil, karena 62 persen perempuan di Indonesia melahirkan dengan bantuan bidan. ${ }^{6}$ Selain memiliki peran dan posisi penting, hambatan untuk menjadi seorang bidan baik hambatan yang terjadi saat menempuh pendidikan maupun setelah menjadi bidan juga terbilang tidak cukup mudah. Hambatan-hambatan tersebut yaitu, adanya persaingan kerja yang ketat, masih sedikitnya pendidikan kebidanan untuk jenjang Strata 1, 2, dan 3, lambatnya proses pengeluaran STR hingga kemungkinan mengalami trauma akibat kegagalan dalam memberikan pertolongan. ${ }^{7,8,9}$

Adanya hambatan-hambatan tersebut dapat mendorong sebuah keyakinan akan hasil yang tidak baik dalam diri mahasiswa Kebidanan dan menyurutkan ekspektasi mereka untuk menjadi seorang bidan di masa depan. Oleh sebab itu, optimisme sebagai konstruk psikologi yang memiliki pengaruh positif pada kehidupan individu penting untuk dimiliki mahasiswa kebidanan guna mengatasi hambatan-hambatan dalam dunia kebidanan. Oleh karena itu, perlu adanya penelitian untuk mengetahui seberapa besar peran optimisme dalam mempengaruhi aspek-aspek lain pada diri mahasiswa kebidanan yang juga berkontribusi membantu mahasiswa keluar dari permasalahan yang ada pada bidan profesinya. Pada penelitian ini, peneliti akan memeriksa hubungan antara optimisme dengan self-esteem, career decision selfefficacy (CDSE), hardiness, dan resiliensi pada populasi mahasiswa program Diploma III Kebidanan. Berdasarkan latar belakang tersebut, maka masalah yang akan dijawab melalui penelitian ini adalah "Apakah terdapat hubungan antara optimisme dan self-esteem, career decision selfefficacy (CDSE), hardiness, dan resiliensi pada mahasiswa program Diploma III kebidanan?"

\section{Self-esteem}

Aspinwall dan Taylor menjelaskan bahwa self-esteem mampu meningkatkan motivasi dan secara keseluruhan berkaitan dengan tingkat kegigihan atau ketekunan yang mengarah pada tujuan. ${ }^{10}$ Beberapa penelitian sebelumnya juga menyebutkan bahwa optimisme dan self-esteem secara signifikan berkorelasi positif antara 0.48 sampai 0.67 pada mahasiswa tingkat akhir maupun mahasiswa baru. ${ }^{11}$ Seligman dalam Gillham, Shatte, Reivich, \& Seligman juga menjelaskan bahwa munculnya optimisme pada diri individu tergantung dari explanatory style atau cara seorang individu menjelaskan peristiwa-peristiwa dalam hidup mereka. ${ }^{12}$ Seligman ${ }^{13}$ berpendapat bahwa ternyata explanatory style yang mempengaruhi munculnya optimisme terbentuk berdasarkan cara pandang 
individu tentang keberhargaan atau kelayakkan dirinya sebagai seorang individu atau dikenal dengan istilah self-esteem. ${ }^{14}$ Dari sudut pandang tersebut, diduga bahwa optimisme secara positif dan signifikan dapat berkorelasi dengan selfesteem.

\section{Career Decision Self-Efficacy (CDSE)}

Keyakinan seseorang akan kemampuan yang dimilikinya (self-efficacy) merupakan penyebab kausal yang memengaruhi secara langsung tujuan dan tindakan dalam pemilihan karir meliputi keputusan karir (career decision), disebut juga efikasi diri pengambilan keputusan karir (CDSE). ${ }^{15}$ Scheier dan Carver mengatakan bahwa ekspektasi positif terhadap hasil yang akan dicapai, diharapkan berjalan seiringan dengan keyakinan dalam usaha yang dilakukan secara kontinu untuk mempertahankan dan menyokong harapan positif yang dimiliki. ${ }^{16}$ Kuatnya keterkaitan kedua faktor ini terbukti dalam penelitian Creed, Patto, dan Bartrum, yang menemukan bahwa siswa yang memiliki level optimisme tinggi, memiliki perencanaan dan eksplorasi karir yang tinggi, lebih mampu dalam menentukan keputusan karir dan lebih memiliki tujuan karir. ${ }^{17}$

\section{Hardiness}

Dalam menghadapi berbagai tekanan dalam hidup dibutuhkan sifat optimis dan tangguh (hardy) dalam diri setiap individu. Menurut Bissonnette, Optimisme dan Hardiness merupakan variabel yang menguatkan sifat-sifat positif dan menahan sifat-sifat negatif yang merupakan efek dari stressor serta mengatasi (coping) situasi tersebut dengan cara yang baik. ${ }^{18}$ Keduanya memiliki kesamaan dimana orang-orang yang tinggi pada skor optimisme dan hardiness cenderung akan menggunakan strategi problem-focused coping.
Selanjutnya berdasarkan penelitian dari Stasiowski, menunjukan bahwa orang-orang dengan tingkat yang lebih tinggi dari optimisme dan hardiness menunjukan pula tingkat yang lebih rendah dari psychological distress. ${ }^{19}$ Hardiness dan optimisme diidentifikasi sebagai yang mempromosikan faktor General Health, yang memungkinkan individu untuk tetap baik secara psikologis dan sehat secara fisik meski menghadapi peristiwa hidup yang negative..$^{20,21}$

\section{Resiliensi}

Banyaknya tekanan pada individu yang menyebabkan stress membuat pentingnya resiliensi dimiliki oleh setiap individu, khususnya pada mahasiswa program Diploma III Kebidanan yang disiapkan untuk menjadi calon bidan. Resiliensi didefinisikan sebagai kemampuan individu dalam mengatasi stres dan kesulitan seperti keadaan normal sebelumnya tanpa adanya perasaan negatif yang dirasakan oleh individu tersebut. ${ }^{22}$ Resiliensi juga penting dimiliki karena bermanfaat untuk menghadapi, mengatasi, dan memperkuat diri individu dalam mengatasi kesulitan yang terjadi dalam hidup agar tetap dapat menjalankan fungsi sosial dan pribadi dengan efektif..$^{23}$ Salah satu cara yang dapat dilakukan untuk meminimalkan dampak stress yang dirasakan oleh individu, khususnya mahasiswa pogram Diploma III Kebidanan adalah memiliki optimisme dan resiliensi dalam diri individu. Optimisme dan resiliensi mampu membantu individu untuk menghadapi situasi yang menyulitkan bagi dirinya dan memiliki ekspektasi yang positif untuk masa depan. Selanjutnya berdasarkan penelitian Sabouripour menyebutkan bahwa adanya hubungan antara optimisme dan resiliensi, sehingga pentingnya menjadi optimis dalam meningkatkan resiliensi. ${ }^{24}$ 


\section{Metode Penelitian}

Penelitian ini merupakan penelitian kuantitatif dan korelasional. Karakteristik partisipan untuk penelitian ini adalah mahasiswa program Diploma III kebidanan semester empat dan enam di wilayah provinsi DKI Jakarta, Jawa Barat, Banten, dan Sumatera Barat, serta masih berstatus sebagai mahasiswa aktif sampai dengan pengambilan data penelitian dilakukan. Keempat wilayah provinsi tersebut dipilih karena berdasarkan survei UNICEF angka kematian di wilayah tersebut cenderung lebih tinggi dibandingkan wilayah-wilayah lain di Indonesia. ${ }^{25}$ Metode pemilihan sampel (sampling) yang dilakukan oleh peneliti adalah dengan nonprobability atau non-random sampling yakni convenience sampling. Peneliti menyebarkan sebanyak mungkin kuesioner dengan target awal sebanyak 400 kuesioner kepada sampel di keempat wilayah. Jumlah data yang diterima kembali oleh peneliti adalah sebanyak 643, kemudian data yang lengkap terisi dan dapat diolah adalah sebanyak 571. Data yang telah terkumpul kemudian diolah secara kuantitaif menggunakan Program Statistical Package for Social Science (SPSS) dengan teknik statistik deskriptif, dan pearson correlation untuk melihat signifikansi hubungan linear antara variabel.

Hipotesis yang diajukan pada penelitian ini adalah $\left(\mathrm{H}_{\mathrm{a}}\right)$ Terdapat hubungan yang signifikan antara optimisme dan keempat prediktor (selfesteem, CDSE, hardiness, dan resiliensi) pada mahasiswa Kebidanan dan $\left(\mathrm{H}_{\mathrm{o}}\right)$ Tidak terdapat hubungan yang signifikan antara optimisme dan keempat prediktor (self-esteem, CDSE, hardiness, dan resiliensi) pada mahasiswa Kebidanan.

\section{Pengukuran}

Optimisme alat ukur optimisme yang digunakan adalah alat ukur LOT-R yang dikembangkan oleh Scheier, Carver, dan Bridges dan telah di adaptasi di Indonesia oleh Isma serta dilakukan uji keterbacaan $(n=12)$, uji reliabilitas dan validitas $(\mathrm{n}=153 ; \alpha=0.51 ;$ validitas $\geq 0.2)$ kembali oleh peneliti. ${ }^{1,26}$

Self-esteem alat ukur self-esteem yang digunakan adalah alat ukur Rosenberg's Selfesteem Scale (RSE) yang dikembangkan oleh Rosenberg dan telah di adaptasi di Indonesia oleh Hutahaean serta dilakukan uji keterbacaan $(n=12)$, uji reliabilitas dan validitas $(\mathrm{n}=153 ; \alpha=0.682$; validitas $\geq 0.2)$ kembali oleh peneliti. ${ }^{27,28}$

CDSE alat ukur CDSE yang digunakan adalah CDSE-SF (Career Decision Self Efficacy Short Form) yang dikembangkan oleh Betz, Klein, \& Taylor telah diadaptasi di Indonesia oleh Sawitri dan digunakan dalam penelitian Atikah. Pada alat ukur ini dilakukan uji keterbacaan $(n=12)$, uji reliabilitas dan validitas $(\mathrm{n}=153 ; \alpha=0.815$; validitas $\geq 0.2)$ kembali oleh peneliti. ${ }^{29,30}$

Hardiness alat ukur yang digunakan adalah Dispositional Resilience Scale 15-Revised yang dikembangkan oleh Paul T. Bartone Ph. D dan telah di adaptasi di Indonesia oleh Lukman serta dilakukan uji keterbacaan $(\mathrm{n}=12)$, uji reliabilitas dan vaiditas $(\mathrm{n}=153 ; \alpha=0,61 ;$ validitas $\geq 0.2)$ kembali oleh peneliti. ${ }^{31,32}$

Resiliensi alat ukur yang digunakan adalah Connor-Davidson Resilience Scale (CD-RISC) yang dikembangkan oleh Connor dan Davidson dan telah diadaptasi oleh Campbell-Sills dan Stein, serta sudah diterjemahkan ke dalam Bahasa Indonesia milik Pusat Krisis Fakultas Psikologi Universitas Indonesia. Alat ukur ini juga telah dilakukan uji 
keterbacaan $(n=12)$, uji reliabilitas dan vaiditas $(\mathrm{n}=153 ; \alpha=\alpha=0,807 ;$ validitas $\geq 0.2)$ kembali oleh peneliti. ${ }^{33,34}$

\section{Hasil}

Sebagian besar partisipan berusia 17-20 dengan jumlah 472 partisipan. Berdasarkan provinsi dengan jumlah partisipan terbanyak adalah dari Sumatera Barat sebanyak 283.

\begin{tabular}{lcc}
\multicolumn{3}{l}{ Tabel 1. Karakteristik Responden } \\
\hline Variabel & $\mathbf{n}$ & $\mathbf{\%}$ \\
\hline Usia & & \\
18 tahun & 18 & 3.2 \\
19 tahun & 223 & 39.1 \\
20 tahun & 231 & 40.5 \\
21 tahun & 71 & 12.4 \\
22 tahun & 21 & 3.7 \\
23 tahun & 6 & 1.1 \\
25 tahun & 1 & 0.2
\end{tabular}

\section{Provinsi}

\begin{tabular}{lcc} 
Banten & 71 & 12.40 \\
DKI Jakarta & 180 & 31.50 \\
Jawa Barat & 37 & 6.50 \\
Sumatera Barat & 283 & 29.60 \\
\hline
\end{tabular}

Nilai mean optimisme partisipan adalah sebesar 17,52 dan standar deviasi (SD) 2,96. Berdasarkan persebaran skor total optimisme didapatkan pula persebaran skor optimisme partisipan yang dibagi ke dalam tiga kategorisasi yaitu rendah, sedang, dan tinggi. Sebagian besar partisipan penelitian memiliki tingkat optimisme sedang (cukup optimis) yaitu sebanyak 375 orang $(66 \%)$.
Tabel 2. Gambaran Umum Optimisme

\begin{tabular}{llll}
\hline $\begin{array}{l}\text { Kategorisasi } \\
\text { Skor }\end{array}$ & $\begin{array}{l}\text { Rentang } \\
\text { Skor }\end{array}$ & n & \% \\
\hline Rendah & $8-14$ & 102 & 18 \\
Sedang & $15-20$ & 375 & 66 \\
Tinggi & $21-24$ & 94 & 16 \\
\hline
\end{tabular}

Nilai mean self-esteem partisipan adalah sebesar 37 dengan SD sebesar 3.4. Persebaran skor self-esteem partisipan menunjukkan bahwa sebagian besar partisipan penelitian memiliki tingkat self-esteem yang berada pada kategorisasi skor sedang yaitu sebanyak 436 orang (76.3\%).

\begin{tabular}{lccc}
\multicolumn{4}{c}{ Tabel 3. Gambaran Umum Self-esteem } \\
\hline $\begin{array}{c}\text { Kategorisasi } \\
\text { Skor }\end{array}$ & $\begin{array}{c}\text { Rentang } \\
\text { Skor }\end{array}$ & n & $\%$ \\
\hline Rendah & $15-25$ & 74 & 13 \\
Sedang & $26-33$ & 436 & 76.3 \\
Tinggi & $34-37$ & 61 & 10.7 \\
\hline
\end{tabular}

Nilai mean skor efikasi diri pengambilan keputusan karir partisipan adalah sebesar 119.38 dan standar deviasi (SD) 12.458. Berdasarkan tabel 4. dapat dilihat bahwa sebagian besar partisipan penelitian memiliki tingkat efikasi diri pengambilan keputusan karir yang sedang (cukup memiliki keyakinan dalam pengambilan keputusan karir) sebanyak 410 orang (72.2\%).

Tabel 4. Gambaran Umum CDSE

\begin{tabular}{llll}
\hline $\begin{array}{l}\text { Kategorisasi } \\
\text { Skor }\end{array}$ & $\begin{array}{l}\text { Rentang } \\
\text { Skor }\end{array}$ & n & \% \\
\hline Rendah & $40-107$ & 76 & 13.3 \\
Sedang & $108-131$ & 410 & 72.2 \\
Tinggi & $132-150$ & 85 & 15.3 \\
\hline
\end{tabular}


Berdasarkan hasil perhitungan didapat nilai rata-rata skor total (mean) hardiness partisipan adalah sebesar 31,39 dengan $\mathrm{SD}=4$. Berdasarkan tabel 5. dapat dilihat bahwa sebagian besar partisipan memiliki tingkat hardiness dengan kategori sedang, yaitu sebanyak 344 orang (6.25\%).

Tabel 5. Gambaran Umum Hardiness

\begin{tabular}{lllc}
\hline $\begin{array}{l}\text { Kategorisasi } \\
\text { Skor }\end{array}$ & $\begin{array}{l}\text { Rentang } \\
\text { Skor }\end{array}$ & n & \% \\
\hline Rendah & $16-27$ & 99 & 17.34 \\
Sedang & $28-34$ & 344 & 60.25 \\
Tinggi & $35-42$ & 128 & 22.42 \\
\hline
\end{tabular}

Berdasarkan perhitungan tabel 6 , sebagian besar partisipan penelitian memiliki tingkat resiliensi yang berada pada tingkat sedang yaitu sebanyak 405 orang (71\%). Kemudian sebanyak 93 orang $(16,4 \%)$ memiliki tingkat resiliensi yang tinggi dan sebanyak 73 orang $(13,2 \%)$ memiliki tingkat resiliensi yang rendah.

Tabel 6. Gambaran Umum Resiliensi

\begin{tabular}{llll}
\hline $\begin{array}{l}\text { Kategorisasi } \\
\text { Skor }\end{array}$ & $\begin{array}{l}\text { Rentang } \\
\text { Skor }\end{array}$ & n & \% \\
\hline Rendah & $19-34$ & 73 & 13.2 \\
Sedang & $35-44$ & 405 & 71 \\
Tinggi & $45-50$ & 93 & $16.4 \%$ \\
\hline
\end{tabular}

Berdasarkan hasil utama dari penelitian ini diperoleh hasil, bahwa terdapat hubungan yang positif dan signifikan antara variabel optimisme dengan keempat variabel lainnya, yaitu self-esteem, CDSE, hardiness, dan resiliensi pada mahasiswa kebidanan. Adanya korelasi signifikan tersebut membuat hipotesis null $\left(\mathrm{H}_{0}\right)$ ditolak dan hipotesis alternatif $\left(\mathrm{H}_{\mathrm{a}}\right)$ diterima, dengan interpretasi bahwa terdapat hubungan positif dan signifikan yang linear antara optimisme dengan keempat variabel prediktor, sehingga apabila skor dari self-esteem, CDSE, hardiness, dan resiliensi mahasiswa kebidanan meningkat maka skor optimisme mahasiswa kebidanan juga akan meningkat dan berlaku sebaliknya.

Tabel 7. Hasil Uji Korelasi Optimisme dan Keempat Variabel Prediktor

\begin{tabular}{lccr}
\hline \multicolumn{1}{c}{\begin{tabular}{c} 
Kategorisasi \\
\multicolumn{1}{c}{ Skor }
\end{tabular}} & $\mathbf{r}$ & Sig $(\boldsymbol{p})$ & \multicolumn{1}{c}{$\mathbf{r}^{2}$} \\
\hline Optimisme \& Self- & 0.376 & $.000^{* *}$ & 0.14 \\
Esteem & 0.203 & $.000^{* *}$ & 0.0412 \\
Optimisme \& CDSE & 0.380 & $.000^{* *}$ & 0.144 \\
Optimisme \& Hardiness & 0.235 & $.000^{* *}$ & 0.05 \\
Optimisme \& Resiliensni & & & \\
\hline
\end{tabular}

**Signifikan pada L.o.S .01 (two tailed)

Berdasarkan hasil perhitungan korelasi juga diperoleh nilai $\mathrm{r}^{2}$ dari keempat variabel prediktor. Nilai $\mathrm{r}^{2}$ pada tabel 7 menunjukkan bahwa $14 \%$ varians skor self-esteem dapat diprediksi oleh skor optimisme, $4.12 \%$ varians skor CDSE dapat diprediksi oleh skor optimisme, $14.4 \%$ varians skor hardiness dapat diprediksi oleh skor optimisme, dan $5 \%$ varians skor resiliensi dapat diprediksi oleh skor optimisme.

\section{Pembahasan}

Berdasarkan hasil dari penelitian ini, diketahui bahwa optimisme memiliki hubungan atau korelasi secara positif dengan keempat variabel. Hasil penelitian sejalan dengan hasil penelitian sebelumnya yang menyatakan bahwa terdapat hubungan signifikan positif antara optimisme dengan self-esteem dan resiliensi. ${ }^{1,12,25}$ Creed, Patto, dan Bartrum menyatakan bahwa siswa dengan optimisme tinggi lebih memiliki 
perencanaan dan eksplorasi karir yang tinggi. ${ }^{18} \mathrm{Hal}$ tersebut juga mengindikasikan bahwa optimisme memiliki hubungan yang positif dengan career decision self efficacy. Hasil penelitian ini juga sesuai dengan pendapat Bissonette yang menyatakan bahwa optimisme dan hardiness merupakan faktor yang menguatkan sifat-sifat positif pada individu. Tingginya optimisme pada individu dapat juga meningkatkan hardiness pada individu. ${ }^{19}$

Hasil penelitian ini dapat diinterpretasikan bahwa apabila skor dari keempat variabel selfesteem, career decision self-efficacy, hardiness, dan resiliensi meningkat maka skor optimisme mahasiswa kebidanan juga akan meningkat dan berlaku sebaliknya. Oleh karena itu, dapat disimpulkan bahwa optimisme dapat memprediksi variabilitas skor atau tingkat self-esteem, career decision self-efficacy, hardiness, dan resiliensi pada diri mahasiswa kebidanan. Hal ini berarti bahwa semakin optimis individu, maka akan semakin berharga individu tersebut dalam memandang kehidupannya, semakin yakin terhadap kemampuan dirinya, semakin tangguh individu tersebut dalam menghadapi berbagai tekanan, dan semakin cepat individu tersebut bangkit dari keterpurukan akibat masalah yang ia hadapi.

Berdasarkan hasil perhitungan juga dapat disimpulkan bahwa dari keempat variabel, terdapat satu variabel yang memiliki varians skor korelasi yang terbesar yaitu variabel hardiness (14.4\%). Dapat disimpulkan bahwa variabel hardiness dapat diprediksi sebesar $14.4 \%$ berdasarkan hubungannya dengan optimisme. Hasil yang telah ditemukan sesuai dengan teori yang menyatakan bahwa optimisme dan hardiness adalah dua variabel yang mempengaruhi cara orang berinteraksi dengan lingkungan, khususnya untuk situasi yang penuh dengan tekanan. ${ }^{35}$ Dengan begitu, meskipun sedang menghadapi situasi yang sulit orang optimis akan tetap yakin bahwa dapat menyelesaikannya dan pada akhirnya akan mendapat sesuatu yang baik. ${ }^{36}$

\section{Kesimpulan dan Saran}

Hasil penelitian menunjukkan bahwa terdapat hubungan yang signifikan positif antara optimisme dan self esteem, career decision self efficacy (CDSE), hardiness, dan resiliensi pada mahasiswa program Diploma III kebidanan. Hal ini berarti bahwa semakin optimis individu, maka semakin meningkat pula self esteem, career decision self efficacy, hardiness, dan resiliensi individu tersebut.

Setelah menemukan hubungan antar variabel dalam penelitian ini, maka peneliti memberikan beberapa saran yang dapat dipertimbangkan untuk dilakukan oleh instansi ataupun individu untuk menangani permasalahan yang sedang terjadi dan yang akan terjadi di masa mendatang. Apabila permasalahan ini ditinjau dari sudut pandang psikologi, peneliti merasa perlu untuk dibuatnya suatu seminar, pelatihan atau program intervensi yang dapat membantu para mahasiswa program Diploma III Kebidanan dalam meningkatkan optimisme ataupun keempat variabel lainnya. Program tersebut perlu direalisasikan, mengingat adanya pengaruh atau dampak positif yang dapat dimunculkan optimisme dan keempat variabel lainnya pada kehidupan maupun performa seorang individu. Selain itu, terkait dengan masalah masa depan karir pada lulusan Diploma III Kebidanan yang lapangan kerjanya sempit, maka peneliti menyarankan bahwa siswa perlu diberikan 
wawasan mengenai beberapa pilihan karir yang tersedia selain menjadi seorang bidan. Hal penting lainnya adalah dengan menggencarkan bimbingan dengan memanfaatkan tenaga ahli psikolog sekolah atau konselor dalam melayani para mahasiswa dalam berbagai permasalahan perkuliahan serta karir di kemudian hari berupa wawasan profesi kebidanan.

\section{Daftar Pustaka}

1. Scheier, M.F., Carver, C.S., \& Bridges, M.W. (1994). Distinguishing Optimism from Neuroticism (and trait anxiety, self-mastery, and self-esteem): A reevaluation of The Life Orientation Test. Journal of personality and social psychology, 67, 1063-1078.

2. Gillham, J.E., Shatté, A.J., Reivich, K.J., \& Seligman, M.E.P. (2001). Optimism, pessimism, and explanatory style. In E.C. Chang (Ed.), Optimism \& pessimism. Washington, DC: American Psychological Association.

3. Hanssen, M. M., Vancleef, L. M. G., Vlaeyen, J. W. S., Hayes, A. F., Schouten, E. G. W., \& Peters, M. L. 2015. Optimism, motivational coping and well-being: evidence supporting the importance of flexible goal adjustment. Journal Happiness Study. 16. pp. 1525-1537. doi: 10.1007/s10902-014-9572-x

4. Keputusan Menteri Kesehatan Republik Indonesia. (2007). Standar Profesi Bidan. Jakarta, Indonesia: Author.

5. Riset Kesehatan Dasar. (2010). Laporan Nasional Riset Kesehatan Dasar (Rikesdas) Tahun 2010. Jakarta, Indonesia: Author.
6. Arisandhi, L. W. 2015, Oktober 25. Unicef: 62 persen perempuan indonesia melahirkan dengan bantuan bidan. Antara Jatim.com. Available at: http://www.antarajatim.com/lihat/berita/16667 4/unicef-62-persen-perempuan-indonesiamelahirkan-dengan-bantuan-bidan.

7. Surat Edaran Direktorat Jendral Pendidikan Tinggi. 2011. Diunduh dari: http://luk.staff.ugm.ac.id/atur/SEDirjen 1643 ET2011MoratoriumProdiKesehatan.pdf

8. Pramudiarja, AN. U. (2012, Februari 02). Indonesia Akan Mengalami Surplus Bidan Pada 2015. health.detik.com. Diunduh dari: http://health.detik.com

9. Majalahbidan.com. (2012, Februari 20). Indonesia akan mengalami surplus bidan pada 2015. Majalah bidan.com. Diunduh dari http://majalahbidan.com

10. Aspinwall, L. G., \& Taylor, S. E. (1992). Modeling cognitive adaptation: A longitudinal investigation of the impact of individual differences and coping on college adjustment and performance. Journal of Personality and Social Psychology, 63, 989-1003.

11. Heinonen, K., Raikkonen, K., \& KeltikangasJarvinen, L. (2005). Self-Esteem in Early and Late Adolescence Predicts Dispositional Optimism-Pessimism in Adulthood: A 21-Year Longitudinal Study. Personality and Individual Differences, $\quad 39, \quad 511-521$. http://dx.doi.org/10.1016/j.paid.2005.01.026

12. Gillham, J. E., Shatte, A. J., Reivich, K. J., \& Seligman, M. E. P. (2001). Optimism, pessimism, and explanatory styles. In Chang, E.C (Ed), Handbook of optimism \& pessimism: Implication for theory, research, and practice 
(pp. 53-75). Washington, DC, US: Edited Book.

13. Seligman, M. E. P. (2006). Learned optimism: How to change your mind and your life [Ebook]. Diunduh dari: https://duniahartanto.files.wordpress.com/2014 /10/ebookscluborg_learned_optimism_how_to_change_you r_mind_and_your_life.pdf

14. Mruk, C. J. (2013). Self-esteem and positive psychology (4th Ed). New York: Springer Publishing Company.

15. Lent, R. W., Brown, S. D., \& Hackett, G. (1994). Toward a unifying social cognitive theory of career and academic interest, choice, and performance [Monograph]. Journal of Vocational Behavior, 45, 79-122.

16. Scheier, M. F., \& Carver, C. S. 1992. Effects of optimism on psychological and physical wellbeing: Theoretical overview and empirical update. Cognitive Therapy and Research, 16, 201-228.

17. Creed, P. A., Patton, W., \& Bartrum, D. 2002. Multidimensional properties of the LOT-R: Effects of optimism and pessimism on career and wellbeing related variables in adolescents. Journal of Career Assessment, 10, 42- 61. Diunduh dari: http://dx.doi.org/10.1177/10690727020100010 03

18. Bissonnette, M., 1998. Optimism, Hardiness, and Resiliency: A Review of the Literature. Available at: http://www.reachinginreachingout.com/docum ents/optimism\%20hardiness\%20and\%20resili ency.pd
19. Stasiowski, S., 2008. Optimism and Hardiness: Influence on Coping and Psychological Distress. Dissertation. Long Island University.

20. Maddi, S. R., \& Kobasa, S. C. (1984). The hardy executive: health under stress. Homewood: Dow Jones-Irwin.

21. Maddi. S.R., Harvey R.H. Khoshaba D.M., Lu, J.L, Persico, \& M., Brow., 2006. The Personality construct of hardiness III: Relationship with repression, innovativeness, authoritarianism and performance. Journal of Personality, 74 (2), 575-598.

22. Masten, A. S. 2009. Ordinary Magic: Lessons from Research on Resilience in Human Development. Education Canada, 49(3), 2832.

23. Grotberg, E.H. 2001. Resilience programs for children in disaster. Ambulatory Child Health, 7, 75 83. Diunduh dari: http://www.georgiadisaster.info/ResourcesPub lications/ParentsandYouth/children\%20resilien ce.pdf

24. Sabouripour, F., \& Roslan, S. B. 2015. Resilience, optimism and social support among international students. Asian Social Science, 11(15), 159-170. Diunduh dari: http://search.proquest.com/docview/16952336 69? accountid $=17242$

25. Unicef. 2012. Kesehatan Ibu \& Anak. UNICEF Indonesia, (Gambar 2), 1-2. Diunduh dari: http://www.unicef.org/indonesia/id/A5_B_Ri ngkasan_Kajian_Kesehatan_R.pdf

26. Isma, M.N.P. (2013). Hubungan Optimisme dan Subjective Well-Being pada Pasien yang Sedang Menjalani Program Rehabilitasi Medik. Skripsi. Depok: Universitas Indonesia. 
27. Rosenberg, M. (1965). Society and the adolescent self-image. Princeton, NJ: Princeton University Press.

28. Hutahaean, B.S.H. (2012). Pelatihan untuk peningkatan self-esteem pada mahasiswa universitas indonesia yang mengalami distres psikologi. Tesis. Depok: Universitas Indonesia.

29. Betz, N., Klein, K., \& Taylor, K. (1996). Evaluation of a short form of the career decision-making self-efficacy scale. Journal of Career Assessment, 4, 47-57.

30. Sawitri. D.R. (2009). Pengaruh status identitas dan efikasi diri keputusan karir terhadap keraguan pengambilan keputusan karir pada mahasiswa tahun pertama di universitas diponegoro. Jurnal Psikologi Undip, 5.

31. Bartone, P.T. (2009). Big five personality factors, hardiness, and social judgement as predictors of leader performance. Developmental Journal, 30 (6).

32. Lukman, A. (2008). Adaptasi dispositional resilience scale- short form pada pramu sosial usia dewasa muda di panti sosial bina laras harapan sentosa. Tesis. Depok: Universitas Indonesia.

33. Connor, K.M., dan Davidson, J.R.T. (2003). Development of a new resilence scale: the connor-davidson resilience scale (CD-RISC). Depression and anxiety, 18, 76-82.

34. Campbell-Sills, L., \& Stein, M.B. (2007). Psychometric analysis and refinement of the connor-davidson resilence scale (CD-RISC): validation of a 10 item measure of resilience. Journal of Traumatic Stress, 20, 1019-1028.

35. Maddi, Salvatore R. \& Hightower, Mindy. 1999. Hardiness and optimism as expressed in coping patterns. Consulting Psychology
Journal: Practice and Research, Vol 51(2), 1999, 95-105. Diunduh dari: http://dx.doi.org/10.1037/1061-4087.51.2.95

36. Snyder, C. R., \& Lopez, S. J., 2002. Handbook of Positive Psychology. Oxford University. New York. 